\title{
The information technology role in supplier-customer information-sharing in the supply chain management of South African small and medium-sized enterprises
}

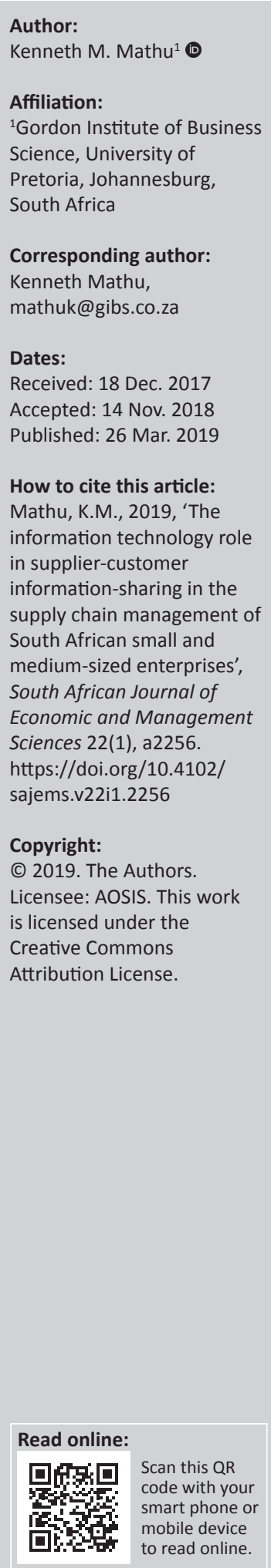

Background: The study background looked at the advent of supply chain management in the last generation which ushered in technology that drives information-sharing within, and across enterprises. The information flow facilitates synchronisation of business activities, such as relationship-building, supply chain management among others.

Aim: The aim of the study was to investigate how information technology (IT) application in the South African small and medium-sized enterprises (SMEs) enhanced supplier-customer information sharing.

Setting: Interviews were conducted with SMEs samples that comprised mixed ownermanagers from food, and general trading SMEs in Gauteng Province of South Africa.

Methods: A qualitative research methodology was used, and a non-probability sampling process was pursued.

Results: The results indicated that IT application in the South African SMEs enhanced suppliercustomer information-sharing, as it improved interaction through supply chain collaboration and integration.

Conclusion: The conclusion of the study highlighted that IT application in enterprises as obtained from South African SMEs enhanced supplier-customer information-sharing.

Keywords: Collaboration; information sharing; information technology; integration; small and medium enterprises; supplier-customer; supply chain management.

\section{Introduction}

Supply chain management (SCM) links suppliers, manufacturers, and customers (Coyle et al. 2017:53). The linkage implies that the suppliers of raw materials supply to the enterprises that manufacture products and services demanded by the customers. That includes the processes of transportation of raw materials, warehousing them at the ordering enterprise, manufacturing, or transforming the raw materials into finished products, and delivering the finished products or services to the customers. These processes are enabled by information sharing within and outside the enterprises involved: supplier and customer.

The Council of Supply Chain Management Professionals (CSCMP) defines supply chain management as 'the integrated managing, and control of the flow of information, materials, and services from the suppliers of raw materials through to the factories, warehouses, and retailers' (Pienaar \& Vogt 2012:8). The reference is a demand type of supply chain where customers demand products or services (demand side) from the manufacturing enterprises, who then receive raw materials from the suppliers (supply side) to manufacture the products or services demanded by the customer. This is another form of interaction between end users or customers, manufacturers, and suppliers. Hence information sharing in a supply chain was reaffirmed by Salam, Panahifar and Byrne (2016: 887-902) as the act of capturing, and disseminating knowledge, and data for decision-makers to plan and control supply chain operations.

This entails the coordinated flow of raw materials from the suppliers, through the production process, up to the end customer or consumers. Sharing accurate and timely information throughout a supply chain can yield significant performance improvements for the enterprise, and for the other members in the value chain (Narkhede et al. 2013). Indeed, it is the process of information sharing between supplier and customer. 
However, many enterprises are still reluctant to share information with their supply chain partners due to the unequal distribution of risks, costs, and benefits among the partners (Salam et al. 2016:887-902). Supply chain is a powerful source of competitive advantage for many enterprises as 'it integrates manufacturing, operations, purchasing, transportation, and distribution into a seamless process' (Wisner, Tan \& Leong 2016:462). Better disclosure between enterprises and suppliers facilitates the identification of risks, and opportunities in the supply chain. The 2017 Global Supply Chain Report published data from some leading multinationals such as BMW, Johnson \& Johnson, and Walmart that indicated that the more intensively they invited suppliers to respond to their requests, the better the quality of their response (Espinosa 2017:16).

Despite increasing complexity in the business environment, enterprises can transmit and share business information easily and effectively through human interactions and internet connections and can achieve virtual integration with the supply chain suppliers (Hsu et al. 2009:102). The indication is that the internet facilitates faster business information sharing between the supply chain (SC) partners. Yang and Jung (2016:236-262) investigated 'how supply chain service capabilities mediated the relationship between supply chain integration (SCI) and multiple measures of firm performance in container shipping supply chain'. The outcome was that SCI has a positive impact on SC service capabilities, which also enhanced market and financial performance (FP). The underlying objective of the enterprises in a supply chain relationship was to optimise profitability for their businesses (American Production and Inventory Control Society [APICS] 2013:57).

The study aimed to establish the role of information technology (IT) applications in supply chain management in South African small and medium enterprises (SMEs) and how it impacted on supplier-customer information sharing. Hence, the objective of the study was to establish the role played by IT applications in South African SMEs in enhancing supply chain collaboration and integration.

\section{Theoretical grounding}

This study was grounded on the theory of supply chain collaboration (SCC) and SCI that addresses the relationship between the supply chain partners, or value chain. The comprehensive description of the theory expresses how supplier-customer information sharing impacts on the supply chain management.

\section{Theory of collaboration and integration}

Wood and Gray (1991:2-22) posited that collaboration stipulated 'the relationship between individual participants' self-interest, and the collective interests of all involved in the collaborative alliance'. The circumstances under which collaboration is convened and the roles of conveners are expressed as the collaborative planning, forecasting, and replenishment (CPFR). The CPFR concept was developed by the American association called Voluntary Inter-industry Commerce Solutions (VICS) and adopted by the Council of Supply Chain Professionals (Wisner et al. 2016:150). The comprehensive definition of CPFR states:

... the cooperative management of inventory through joint
visibility, and replenishment of products throughout the supply
chain. Information shared between suppliers, and retailers' aids
in planning, and satisfying customer demands through a
supportive system of shared information. This allows for
continuous updating of inventory, and upcoming requirements,
essentially making the end-to-end supply chain process more
efficient. In the process, efficiency is created through the
decreased expenditures for merchandising, inventory, logistics,
and transportation across all trading partners. (Wisner et al.
2016:150-151)

CPFR is an IT-driven process (APICS 2013:36).

\section{Supply chain collaboration and supply chain integration}

The American Production and Inventory Control Society (APICS 2013:171) described supply chain collaboration as 'the establishment of working relationship with a supplier organisation, whereby two organisations act as one'. This entails different enterprises sharing information and work plans as it would occur in an individual firm. On the other hand, Mangan et al. (2012:47) posited SCC as 'a relationship between supply chain partners developed over time'. In this situation the working relationship between different enterprises develops after both have familiarised themselves with the other over time.

Supply chain integration is the 'alignment and interlinking of business processes' (Mangan et al. 2012:47). This implies that the business processes of the enterprises involved sharing their functionalities as if operating in a single firm. APICS describes SCI as 'when supply chain partners interact at all levels to maximise mutual benefits' (APICS 2013:172). The reason for supply chain partners working together is to increase benefits for all members involved in the supply chain. According to Yang and Jung (2016) SCI is the relationship within an enterprise, as well as with supply chain partners to streamline the flow of information, materials, and finished products and services to the final customers. In this case the operation process in SCI is seamless as it happens in a single entity.

Silvestro and Lustrato (2014) expressed four enablers of SCI as supply chain coordination, cooperation, collaboration, information sharing, and information visibility. Supply chain coordination entails the synchronisation of activities within an enterprise, and external relationships with other supply chain partners. Cooperation entails working jointly towards the same end. Supply chain collaboration involves two variables such as functions within an enterprise. For example, information sharing encompasses the systems integration within and between supply chain partners. Integration entails, 
for instance, linkages such as sharing of browsers in different entities. Furthermore, information visibility is essentially the use of IT to enhance the supply chain relationship. Visibility is generated by displaying the activities taking place within a supply chain on a computer screen. An example could be, following an order from issuing until delivery to the end user or customer. The four variables provide elaborate examples of intangible resources.

\section{Information technology}

The advent of IT during the last generation has ushered in a new era in the business world, and life in general. It has enhanced the quality of information and communication modes, making the world a global village, and easing operational issues (Lee \& Joshi 2016:1-5). IT through computers and the world wide web (internet) has increased the speed of communication tremendously, making it possible to reach any corner of the world. A key objective of entrepreneurial information management is to ensure that valuable information was acquired and exploited to its fullest (Narkhede et al. 2013). The long-term cooperation and coordination of information sharing in supply chain leads to improvements in competitiveness of the enterprises involved (Lotfi et al. 2013:298-304). Information sharing entails the exchange of data between people, organisations, and technologies through activities such as creation, representation, organisation, maintenance, visualisation, reuse, sharing, communication, and disposal. The stated variables add value to information flow through the processes of exchange, sharing, and collaboration within and between enterprises up to the ultimate end users (Tarek \& Mchirgui 2014). Hence, it is crucial that these roles are performed effectively and efficiently to optimise the benefits accrued.

\section{South African definition of small, micro- and medium enterprises}

There are over 2.2 million small, micro and medium enterprises (SMMEs) in South Africa, of which only around 600000 are formal establishments (BE Research 2016). These numbers indicate that most of the South African SMMEs are informal, and not properly accounted for. According to the RMB Morgan Stanley report of 2017, the South African informal food market contributes $35 \%$ of the total food retail market in the country (Tshandu 2017). However, the country has 2500 modern trade outlets including supermarkets, and 140000 traditional trade outlets that include spaza shops (South African model of micro-sized enterprises) that contributed R316.5 billion (Goko 2017).

The legal requirements for South Africa SMMEs comprise: business registration, registration for tax, learning about labour law, learning about the Consumer Protection Act, learning about health and safety and municipal by-laws (Small Business Site 2017). Other descriptions of SMEs express their nature and purpose. The most common versions are those of the South African Revenue Service (SARS) and the Department of Trade and Industry (DTI) (Forum SA 2009).
However, the legal definition of South African SMMEs was stipulated by the National Small Business Amendment Act 26 of 2003 covering five categories: sector and subsector in accordance with the standard industrial classification, size of class, equivalent of paid employees, turnover and asset value. Hence, an SME bears the following characteristics:

- fewer than 200 employees

- annual turnover of less than R64 million

- capital assets of less than R10 million

- direct managerial involvement by owners. (Act No. 26 2003)

The Department of Trade and Industry (DTI) definition focuses on the number of employees:

- small-sized establishments of 20-49 employees

- medium-sized establishments of 50-199 employees. (BER 2016)

The South African Reserve Bank on the other hand classifies SMMEs based on the number of employees as: microbusinesses (fewer than 5), very small businesses (6-20), small businesses (21-50), and medium businesses (over 200) (SA Reserve Bank 2015).

\section{The roles of small and medium- sized enterprises in South Africa}

Small and medium-sized enterprises account for nearly $90 \%$ of all registered enterprises, which constituted most of all the private sector establishments in South Africa (Jeppensen, Kothuis \& Tran 2012:9). Thus, most of the private businesses in South Africa are SMEs. The SMEs play crucial roles in job creation, poverty alleviation, and contribution to the growth domestic product (GDP) (Sohar \& Rostom 2013). Indeed, this highlights their economic importance as well as socioeconomic contribution to the country (Stats SA, 2017). The National Small Business Chamber (NSBC), a staunch supporter of SMEs, views small businesses as the fuel for economic growth and employment. Simply put the dynamic role of SMEs makes them the engine through which growth objective are realised in South Africa as in other emerging markets (NSBC 2012). The study by Didonet and Diaz (2012:1) posited that SCM practice supported innovations in SMEs. Other previous studies support the view that the implementation of SCM has added a competitive advantage to SMEs, through enhanced relationships with suppliers (Alhourani \& Saxena 2014:1).

\section{Enterprises information flow}

In the past 30 years or so, large organisations owned some of their suppliers or some of their customers (vertically integrated) (Wisner et al. 2016:5). Currently this practice is much less common due to the cost involved in running such complex establishments. Organisations prefer running lean businesses that focus on the core areas and other services such as transportation, inventory, warehousing, and information technology among others that are outsourced (Hill \& Hill 2012). The use of enterprise 
resource planning (ERP) systems enables enterprises to work more effectively and efficiently through enhanced communication, and information exchange (Nigel et al. 2017:364). Citing the complexity in a construction company, Silvestro and Lustrato (2014) point out that information plays a crucial role in enabling the smooth flow of the operations through coordination within partners, and integration across partners. The quality of the information received and the cost-effectiveness in obtaining it determine the efficiency of a project in supply chain management.

\section{Small and medium-sized enterprises' information technology adoption}

The advent of the internet has significantly revolutionised enterprises globally including SMEs. The emergence of electronic commerce (e-commerce), which could be expressed as IT adoption, has been a remarkable value-add to all businesses. According to Chan, Chong and Zhou (2012:329), the adoption of IT by SMEs has significantly enhanced their operations. In United States of America, for example, research in e-commerce sales in 2016 indicated a growth of $14.6 \%$ (Zaroban 2016:1).

Research on internet use indicates that a growing number of businesses continue to embrace technology innovations, and increasingly make IT adoption decisions (Heath 2017:1). The internet has significantly extended business influence and operations globally with some leading economies such as United States of America and Europe having over 80\% of their population involved (Internet World Stats 2017). The use of IT makes the workforce agile, swift, and flexible, some of the qualities that are crucial for an effective agile supply chain (White \& Mohdzain 2009:69-84). It means that the use of internet enables the employees to work and respond to demands faster and more effectively. Research by a South Korean journal on internet banking alluded that the risk of internet banking indirectly influenced adoption behaviour (Lee, Lee \& Kim 2015). It means that internet use becomes addictive.

In most cases, SMEs were forced to engage in electronic business when their dominant clients had adopted e-commerce in their businesses. The South African government's electronic database for procurement forces SMEs and other suppliers to adopt the same system to be compatible (SA e-tender Portal 2015).

\section{Problem statement}

Technology use is crucial for information flow within and between enterprises as demonstrated by IT adoption in the last generation. Hence, this study investigated how supplier-customer information sharing enhanced supply chain collaboration and integration in South African SMEs.

\section{Empirical objectives}

The empirical objectives of the study aimed to establish the role IT application played in supplier-customer information sharing in enhancing SCC and SCI in South African SMEs.

\section{Methodology and design}

This study pursued a qualitative research approach to establish the role IT played in supplier-customer information sharing in enhancing supply chain collaboration and integration of South African SMEs. Kim (2009:328) posited that research methodology comprises processes undertaken by researchers in explaining, predicting, and describing selected phenomena. In this study, the phenomenon investigated was the potential impact on supply chain management of IT application in supplier-customer information sharing in South African SMEs. Neill (2007:4) defined research methodology as the study of methods by which knowledge was acquired. A qualitative methodology was adopted for the study.

Qualitative research entails the researcher's process of interviewing participants to generate data (Lee \& Lings 2008:247). The selected respondents were interviewed at arranged venues, and the interviews were recorded to generate the data. Punch (2010:47) defined research design as the strategy and structure of conducting a research project as stipulated in the process undertaken in this study.

In pursuit of the empirical objectives, the study reviewed literature on supply chain management, SMEs in South Africa, and information flow within and across the supply chain partners. The role of IT application and how it supported other technology applications such as internet use in supply chain management was examined. The resource materials comprised supply chain journals such as International Journal of Operations and Production Management, International Journal of Logistics Management, Journal of Enterprise Information Management, South African government legislations for SMEs, and online journals on supply chain, IT, and internet applications. The latest books published on supply chain management and logistics and operations management, such as Coyle et al. (2017), Nigel et al. (2017), Wisner et al. (2016) and others, were consulted.

The 25 participants were the owner-managers drawn from mixed formal SMEs in mid-2017 that comprised 15 food stores and 10 general traders selected from Gauteng province from a population of 2.25 million SMMEs nationally (BER 2016). More than one type of SME was used to minimise bias from the population of the national database of 2500 modern trade outlets in South Africa (Goko 2017). Hence, nonprobability sampling was used (Saunders, Lewis \& Thornhill 2009). A semi-structured questionnaire was used; interviews lasted not more than $1 \mathrm{~h}$ and were recorded with a digital data recorder. Following the guidelines of Saunders et al. (2009:137) the respondents were well briefed on the purpose of the interview, and the interview location was arranged at 
their premises as it was the most convenient location, as owner-managers of businesses are usually busy. The researcher approached the enterprises via e-mails and telephone to arrange for interviews. A few of the enterprises required pre-interview briefings, which were provided. The briefing comprised a short PowerPoint presentation stating the value proposition (the role of IT in supplier-customer information sharing). If multinational corporations such as Walmart and BMW could benefit from high-level relationships with their suppliers as cited in the Global Supply Chain Report (Espinosa 2017:16), it could also be possible with smaller firms such as SMEs.

The recorded data were transcribed, analysed, coded, and the emerging themes interpreted via content analysis using atlas. ti. The emergence of both major themes, and sub-themes were taken into consideration in the analysis. Notes from a field notebook used to record the interviews were eventually compared with the transcribed data to ascertain the validity and trustworthiness of the study.

Kumar (2005:216) expresses the importance of undertaking research in an ethical manner. Hence, the researcher presented to the respondents a written undertaking from the sponsoring institution, stipulating the confidentiality undertaking of non-disclosure, and anonymity of the respondent during the interview period and afterwards.

\section{Results}

The themes and sub-themes that emanated from the interviews are expressed in Table 1.

\section{Findings of the study}

The data analysis of the study produced seven major themes and several sub-themes. The major themes comprised technology integration; supplier-customer collaboration; information flow, ease of documentation and product alignment; supply chain network, design and flexibility;

TABLE 1: Themes and sub-themes that emerged from the data.

\begin{tabular}{|c|c|}
\hline Themes & Sub-themes \\
\hline Technology or integration & $\begin{array}{l}\text { - Information technology use } \\
\text { - ERP outsourcing } \\
\text { - Staff training }\end{array}$ \\
\hline $\begin{array}{l}\text { Supplier-customer } \\
\text { collaboration }\end{array}$ & $\begin{array}{l}\text { - Joint planning } \\
\text { - Demand coordination } \\
\text { - Faster integration }\end{array}$ \\
\hline Information flow & $\begin{array}{l}\text { - Computer use } \\
\text { - Warehouses coordination } \\
\text { - Stock control }\end{array}$ \\
\hline $\begin{array}{l}\text { Ease of documentation and } \\
\text { product alignment }\end{array}$ & $\begin{array}{l}\text { - Integration with IT systems } \\
\text { - Bar coding and radio frequency identification use } \\
\text { - Data storage }\end{array}$ \\
\hline $\begin{array}{l}\text { Supply chain network, design } \\
\text { and flexibility }\end{array}$ & $\begin{array}{l}\text { - Special keeping units reduction } \\
\text { - SC performance enhancement } \\
\text { - Cooperation with value-chain partners } \\
\text { - Stock control } \\
\text { - Sales and operations planning alignment }\end{array}$ \\
\hline $\begin{array}{l}\text { Third-party and fourth-party } \\
\text { logistics }\end{array}$ & $\begin{array}{l}\text { - Transport optimisation } \\
\text { - Service level agreement } \\
\text { - Use of geographical positioning systems }\end{array}$ \\
\hline IT adoption & $\begin{array}{l}\text { - Ease of procurement and finance administration } \\
\text { - Enhanced administration } \\
\text { - Skilling employees }\end{array}$ \\
\hline
\end{tabular}

3PL/4PL and IT adoption. According to the participants, these were the outcomes from the supplier-customer interactions that had a direct impact on their supply chain as interpreted from the themes that emanated from the data. Those outcomes are expressed in detail under each major theme and examples from some participants provided in the detailed report that follows. Indeed, the elaboration of the themes indicated that the study met its objective and shed light on the crucial role of technology (IT application) in enhancement of information sharing which is essential for effective performance of supply chains.

The study met the empirical objectives: 'To establish that supplier-customer information sharing enhanced supply chain collaboration and integration in South African SMEs'.

The elaboration of the themes supported the proposition of the study and the objective thereof, as argued below.

Technology/integration: The adoption of technology in SMEs enhanced the inter- and intra-organisational cooperation, coordination, and the integration of the supply chain, leading to effective, and efficient operations. This featured in at least 21 participants. One participant remarked:

'I think in the material space and the supplier's space we have embarked on a partner to win campaign and what that means is we have got a very close relationship with our key suppliers. And we have identified who the key suppliers are and therefore we have a very close understanding and relationships with their businesses. We have shared our forecasts with them very openly and they too have done a number of activities on their side such as holding stock, procuring extra raw materials et cetera to really get to a partner to win relationships with our company. That has made us responsive.' (Participant 17, male, grocery store owner)

Supplier-customer collaboration: This was expressed as a relationship built over a long period of time that was beneficial to both customer and supplier for developing their business. The respondents raised issues involving among others transportation, accounts handling, and warehousing. These functions were mutually handled among the parties that initiated collaborative relationships. Over half of the respondents concurred with the sentiment expressed by a respondent:

'Other elements that we have, you may notice that our customers are more demanding on us in terms of slot times for deliveries and making sure that we deliver the product on the day that it ordered or I within a slot time, but we are not good at asking our suppliers to do the same thing. I think there is still an opportunity to get better at scheduling trucks coming in and running them against a roaster, it is fairly simple and also reducing spikiness of products coming in, so we still have 14 or 15 deliveries on a Monday and one or two on a Tuesday, so spread that through the week and I think we can be more efficient on our inbound side as well.' (Participant 5, male, store manager)

IT adoption: The adoption of IT in modern times has been a game changer in business and society at large. The computer application has integrated and enhanced coordination and 
operations in most of the business processes. IT speeds internal alignment of enterprises and cooperation with external partners. Indeed, 15 participants alluded to this view as stated by a respondent:

'From an IT perspective we have SAP as the base, we have a warehouse management system and we have planning tools. Planning tools cover demand planning, production planning, production scheduling and deployment planning, the normal things that we do. We have fully integrated planning, transactional processing, finance, all that sort of stuff that is altogether. All integrated or all inter-phased I suppose I would say.' (Participant 5, female, warehouse manager)

Information flow: The computer network in business enhanced the information flow, for instance in out-of-stock situations, ordering and order-filling between customer and supplier, and facilitating timeous delivery. All the respondents were unanimous that connectivity among the value-chain partners via computers enhanced information flow, as articulated by a respondent:

'In some cases faster moving products moving through the network are going to become a little bit more agile and a little bit more algorithm driven within our warehouse management systems, less about human intervention and more about systems doing the thinking for us. That is definitely going to become a big part of the process and a link between replenishment and what we do within the network is going to be critical.' (Participant 4 , male, warehouse owner)

Ease of documentation and product alignment: This involved the integration of IT systems between the supplier and customer to facilitate smooth ordering process and inventory replenishment in an effort to balance the demand capacity and production. The use of barcode and radio frequency identification (RFID) for the ease of product identification on receipt and dispatch at warehouses was mentioned. In addition, track and trace systems are also used for stock verification in store. A respondent said that:

'In the distribution space we have embarked on number of continuous improvement projects, this talks to lane optimisation transport route optimisation; for warehousing within warehouses we have a number of projects that we run over the last year to decrease travelling time in the warehouse and ensure the fastest route for picking stock for outbound. We use barcode and to some extent RFID to check deliveries and dispatch. Some trucks have [geographical positioning system] GPS. We continue to challenge ourselves.' (Participant 23, male, logistics company owner)

Supply chain network, design and product alignment: All the respondents alluded to the critical need for supply chain design with elaborate networks to supply products and services demanded by the market or customers. The response of a respondent appealed to these fundamental requirements:

'The fact is that it is not controlled by us. I use that term loosely because we have got to manage our own products. There are a lot of steps along this chain, it can go wrong at the distributor, at the store, at a number of a place where these delays can happen and that is where you will see the product. You cannot have individual elements in this value stream being coordinated by different people. One person needs to be the boss of it, I use that term loosely. One person needs to sit and have a look at what happening from literally the planning, the procurement of the first raw material, until it gets to the customer's shelves. So that entire value stream needs to be owned; my view by supply chain.' (Participant 13, female, general store manager)

3PL/4PL: The respondents viewed transportation as a major cost component of the supply chain. They believed that this was better managed independently by a third-party logistics (3PL) or fourth-party logistics (4PL) company that outsources more supply chain services. In this regard, a respondent said:

'In the distribution space we have embarked on number of continuous improvement projects, this talks to lane and transport route optimisation; for warehousing within warehouses we have a number of projects that we run over the last year to decrease travelling time in the warehouse and ensure the fastest route for picking stock for outbound. We use barcode and to some extent RFID to check deliveries and dispatch. Some trucks have GPS. We continue to challenge ourselves.' (Participant 1, male, logistics company owner)

\section{Managerial implications}

The SMEs' managers and the owner-managers of the enterprises interviewed expressed their experience and impact of supplier-customer information sharing as the interviews reflect. Their real-time experience answered the objectives that were set up. The use of information technology, and internet connectivity enhanced the collaboration and integration within and outside the enterprises involved in the supply chain. Statements such as systems aiding human thinking, and transport optimisation to and from warehouses demonstrated value-add from the cooperation between supplier and customer. They also mentioned the use of track and trace technology such as barcodes and RFID for identifying products at the warehouses and geographical positioning systems (GPS) for monitoring delivery trucks' movements to ensure timeous delivery of products to destinations. These are crucial management tools for logistics management which is the part of supply chain management responsible for warehousing and distribution processes. Thus, use of technology enhanced the products and services flow in the supply chain of the enterprises involved.

\section{Limitation of the study}

The manufacturing sector was not included during the investigation which could have made the study more inclusive. The study of SMEs from the country's leading business hub of Gauteng province excluded the network of retail chain stores, which would have given it a more comprehensive national outlook. However, the samples used testified to the crucial role played by IT and other technologies such as internet and track and trace in enhancing information sharing between and within enterprises through coordination, integration, and collaboration in the supply chain. This was supported by the data that emerged from the study and the testimony highlighted by the participants. 


\section{Conclusion}

The study explored the supply chains of SMEs in food and general traders in Gauteng province of South Africa to establish how supplier-customer information sharing can enhance the supply chain of South African SMEs. A sample of 25 enterprises drawn from the food and general trading sectors was interviewed, and a qualitative research methodology was adopted. Various definitions of SMEs were covered with more emphasis on South African SMEs. The IT adoption by enterprises during the last generation or so was expressed as the medium for information flow among the enterprises. It was found that information sharing took place through cooperation, coordination, collaboration, and integration, and these terminologies were well defined, and distinguished in the literature.

The underpinning theory of collaboration and integration, and CPFR concept were articulated. CPFR is adopted and recommended by Supply Chain Council as an appropriate measure of inventory levels at retail stores to facilitate timeous replenishment. The CPFR role in speeding up stock replenishments in stores was expressed. After the interviews with the respondents, data were transcribed, coded and analysed through content analysis, whereupon seven major themes and several sub-themes emerged. The themes that emerged and the views expressed by the respondents concluded that the supplier-customer information sharing enhanced supply chain collaboration and integration.

Based on the study outcome, it is apparent that the use of technology such as IT, and internet in enterprises enhanced supplier-customer information sharing, which is a medium for improved supply chain collaboration and integration. Hence, technology use in enterprises continuously improves the body of knowledge as emergence of new innovations is experienced.

\section{Recommendations}

As it emerged that IT and related technologies enhanced supplier-customer information sharing through integration and collaboration upon which supply chain management thrives, it would be crucial for all SMEs to embrace technology. With the technology-centred fourth industrial revolution looming, it is crucial for SMEs to speed up skilling their employees in IT and related technologies to remain competitive in the future.

\section{Acknowledgements \\ Competing interests}

The author declares that he has no financial or personal relationships that may have inappropriately influenced him in writing this article.

\section{References}

Alhourani, F. \& Saxena, U., 2014, 'Supply Chain Management practices in US Industrial SMEs', International Journal of Business Research 14(2), 7-18. https://doi.org/ 10.18374/IJBR-14-2.1
American Production and Inventory Control Society (APICS), 2013, The Essential Supply Chain Reference (Dictionary), Terry College of Business, University of Georgia.

Bureau of Economic Research (BER), 2016, The small, medium and micro enterprise sector of South Africa, viewed 18 July 2017 from http://www.seda.org.za/ Publications/Publications/The $\% 20$ Small, $\% 20$ Medium $\% 20$ and $\% 20$ Micro\%20 Enterprise $\% 20$ Sector $\% 20$ of $\% 20$ South $\% 20$ Africa $\% 20$ Commissioned $\% 20$ by $\% 20$ Seda.pdf

Chan, F.T.S., Chong, A.Y.L. \& Zhou, L., 2012, 'An empirical investigation of factors affecting e-collaboration diffusion in SMEs', International Journal of Production Economics 138, 329-344. https://doi.org/10.1016/j.ijpe.2012.04.004

Coyle, J.J., Langley, C.J., Novack, R.A. \& Gibson, B.J., 2017, Supply Chain Management: A logistics perspective, 10th edn., Cengage Learning, Boston, MA.

Didonet, S.R. \& Diaz, G., 2012, 'Supply chain practice supports innovations in SMEs', Journal of Technology Management \& Innovation 7(3), viewed 13 June 2017 from http://www.scielo.cl/scielo.php?script=sci_arttext\&pid=S0718-27242012000300009

E-Tender Portal, 2015, Treasury launches central database and e-tender publication portal, viewed 02 December 2017 from http://www.gov.za/speeches/launchingcentral-supplier-database-and-etender-publication-portal-8-apr-2015-0000

Espinosa, P., 2017, 'CDP's supply chain member organisations', Global Supply Chain Report, p. 16, viewed 02 December 2017 from https://b8f65cb373b1b7b15febc70d8ead6ced550b4d987d7c03fcdd1d.ssl.cf3.rackcdn.com/cms/reports/ documents/000/001/500/original/CDP-Supply-chain-report-2017. PDF?1485248719

Goko, C., 2017, 'Spaza shops growing strongly, study shows', Business Retail Behaviour, viewed 02 December 2017 from https://www.businesslive.co.za/bd/businessand-economy/2017-06-26-spaza-shops-growing-strongly-study-shows/

Heath, D., 2017, What are the positive effects of the internet in business, viewed 01 December 2017 from https://bizfluent.com/info-8236794-positive-effectsinternet-business.html

Hill, A. \& Hill, T., 2012, Operations management, 3rd edn., Palgrave Macmillan, New York.

Hsu, L.L., Chiu, C.M., Jason, C.H., Chen, C.H. \& Liu, C.C., 2009, 'The impacts of supply chain management systems on information sharing and integrated-performance', Human Systems Management 28, 101-121, viewed 07 November 2017 from http://en.wikibooks.org/w/index.php?title=Research_Methods/Types_of http://en.wikibooks.org/w
Research\&oldid=2616361

Internet World Stats, 2017, World internet usage and population statistics, June 30 viewed 02 December 2017 from http://www.internetworldstats.com/stats.htm

Jeppesen, S., Kothuis, B. \& Tran, A.N., 2012, Corporate social responsibility and competitiveness for SMEs in developing countries: South Africa and Vietnam, viewed 11 October 2017 from http://www.afd.fr/webdav/shared/PUBLICATIONS/ RECHERCHE/Scientifiques/Focales/16-VA-Focales.pdf

Kim, S., 2009, 'Individual-level factors and organisational performance in government organisations', Journal of Public Administration Research and Theory 15(2), 254-261.

Kumar, R., 2005, Research methodology: A step by step guide for beginners, 2nd ed., Sage, London.

Lee, K. \& Joshi, K., 2016, 'Importance of globalization in the information technology convergence era', Journal of Global Information Technology Management 19(1), 1-5. https://doi.org/10.1080/1097198X.2016.1134168

Lee, K.S., Lee, H.S. \& Kim, S.Y., 2015, Factors influencing the adoption behavior of mobile banking: A South Korean perspective, viewed 11 July 2017 from http:// www.icommercecentral.com/open-access/factors-influencing-the-adoptionbehavior-of-mobile-banking-a-south-korean-perspective. php?aid=38487

Lee, N. \& Lings, I., 2008, Doing business research: A guide to theory and practice, Sage, London.

Lotfi, Z., Mukhtar, M., Sahran, S. \& Zadeh, A.T., 2013, 'Information sharing in supply chain management', Procedia Technology 11, 298-304. https://doi.org/10.1016/j. protcy.2013.12.194

Mangan, J., Lalwani, C., Butcher, T. \& Javadpour, R., 2012, Global logistics and Supply Chain Management, John Wiley, Chichester, UK.

Narkhede, B.E., Rant, R.D., Patil, B.T. \& Mahajan, S.K., 2013, 'Performance improvement in small and medium-sized enterprises due to information system implementation', Information System for Performance Improvement 52(9), 24-32, viewed 13 August 2017 from http://onlinelibrary.wiley.com/doi/10.1002/ pfi.21385/full

National Small Business Chamber (NSBC), 2012, The importance of small business in South Africa, viewed 13 August 2017 from http://blog.sagesouthafrica.co. $\mathrm{za} / 2012 / 08 / 31 /$ the-importance-of-small-business-in-south-africa/

Neill, T., 2007, Power and empowerment, viewed 02 November 2017 from https://www.books.google.co.za/books/about/power_and_empowerment. html?d=sb1gPQAACAAJS/redir_esc=y

Nigel, S., Brandon-Jones, A., Johnston, R., Singh, H. \& Phihlela, K., 2017, Operations management: Global and Southern African perspectives, 3rd edn., Pearson South Africa, Cape Town

Pienaar, W.J. \& Vogt, J.J., 2012, Business logistics management: A value chain perspective, 4th edn., Oxford University Press, Cape Town, SA.

Punch, K.F., 2010, Developing effective research proposals, 2nd edn., Sage, Los Angeles, CA.

Republic of South Africa. The Presidency. 2003. Act No. 26 of 203. National Small Business Amendment Act, Government Gazette No. 25763, 26 November, Pretoria. 
Salam, A., Panahifar, F. \& Byrne, P.J., 2016, 'Retail supply chain service levels: The role of inventory storage', Journal of Enterprise Information Management 29(6), 887-902. https://doi.org/10.1108/JEIM-01-2015-0008

Saunders, M., Lewis, P. \& Thornhill, A., 2012, Research methods for business students, 5th edn., Pearson Education, Harlow, UK.

Silvestro, R. \& Lustrato, P., 2014, 'Integrating financial and physical supply chains: The role of banks in enabling supply chain integration', International Journal of Operations \& Production Management 34(3), 298-324. https://doi.org/10.1108/ IJOPM.04.2012.0131

Small Business Site, 2017, Your SME check list - what you need to comply, viewed 02 December 2017 from http://www.thesmallbusinesssite.co.za/2017/11/30/smechecklist-need-comply/

Sohar, N. \& Rostom, A.M., 2013, SMEs contributions to employment, job creation, and growth in the Arab World, World Bank Group, Open Knowledge Repository, viewed 12 October 2017 from https://openknowledge.worldbank.org/handle/ $10986 / 16897$

South African Reserve Bank, 2015, The role of small businesses in the economy, viewed 21 November 2017 from https://www.resbank.co.za/ Lists/Speeches/Attachments/452/Role $\% 20$ of $\% 20$ small\%20business $\% 20$ 2015\%20.pdf

Statistics South Africa (StatsSA), 2017, GDP contracted by $0.7 \%$ in the first quarter viewed 01 December 2017 from http://www.statssa.gov.za/?cat=30
Tarek, S. \& Mchirgui, N., 2014, 'Supply chain management optimization within information system development', International Journal of Econometrics and Financial Management 2(2), 59-71.

The Forum SA, 2009, South Africa's small and medium-sized enterprises (SMEs), viewed 17 June 2017 from http://www.theforumsa.co.za/forums/showthread. php/5871-SME-Small-and-Medium-sized-Enterprises

Tshandu, P.V., 2017, 'David vs Goliath in grocery market probe', Business Premium viewed 02 December 2017 from https://www.businesslive.co.za/bt/businessand-economy/2017-06-11-david-v-goliath-in-grocery-market-probe/

White, D. \& Mohdzain, M.B., 2009, 'An innovative model of supply chain management: A single case study in electronic sector', International Journal of Information Technology and Management 8(1), 69-84. https://doi.org/10.1504/JITM.2009.022271

Wisner, J.D., Tang, K.-C. \& Leong, G.K., 2016, Principles of Supply Chain Management: A balanced approach, 4th edn., Cengage Learning, Boston, MA.

Wood D.J. \& Gray, B., 1991, 'Collaborative alliances: Moving from practice to theory', Journa of Applied Behavioral Science 27(1), 3-22. https://doi.org/10.1177/0021886391271001

Yang, C.-H. \& Jung, C., 2016, 'The antecedents and consequences of supply chain service capabilities in the context of container shipping', The International Journal of Logistics Management 27(2), 236-262. https://doi.org/10.1108/IJLM 0920140151

Zaroban, S., 2016, 'U.S. e-commerce grows $14.6 \%$ in 2015', E-commerce Sales, viewed 18 October 2017 from https://www.internetretailer.com/2016/02/17/use-commerce-grows-146-2015 